\title{
Discovery of microphytobenthos migration in the subtidal zone
}

\author{
Sorcha Ni Longphuirt ${ }^{1, *}$, Aude Leynaert ${ }^{1}$, Jean-Marc Guarini ${ }^{2}{ }$ Laurent Chauvaud $^{1}$, \\ Pascal Claquin ${ }^{3}$, Olivier Herlory ${ }^{4}$, Erwan Amice ${ }^{1}$, Pierre Huonnic ${ }^{1}$, Olivier Ragueneau ${ }^{1}$
}

${ }^{1}$ LEMAR, Laboratoire des Sciences de l'Environnement Marin, UMR 6539 CNRS, Institut Universitaire Européen de la Mer, Technopôle Brest-Iroise, Place Nicolas Copernic, 29280 Plouzané, France

${ }^{2}$ Observatoire Océanologique Laboratoire Arago, BP 44, 66654 Banyuls/Mer, France

${ }^{3}$ LBBM, Laboratoire de Biologie et de Biotechnologies Marines, Université de Caen Basse-Normandie, Esplanade de la paix, 14032 Caen, France

${ }^{4}$ LBEM, Laboratoire de Biologie et Environnement Marins, FRE 2727 CNRS, Université de La Rochelle, Avenue M. Crépeau, 17042 La Rochelle, France

\begin{abstract}
Microphytobenthos (MPB) contribute significantly to primary production in many estuarine and coastal waters. Although the vertical migration of microphytobenthos is well integrated into benthic studies of intertidal areas, the presence and importance of such migration has not yet been investigated in subtidal areas. In situ measurements and sampling in the Bay of Brest, French Atlantic coast, in November 2003 and May, July and September 2004 and subsequent laboratory experiments showed that pulse amplitude modulated (PAM) fluorometry can be employed to follow vertical migration of subtidal MPB. Steady-state fluorescence $(F)$ was highly correlated with chlorophyll a (chl a) concentrations in the top $200 \mu \mathrm{m}$ of sediments and could be used to detect in situ changes in MPB biomass. When (as in the present study) subtidal variations in light and temperature are negligible compared to those in intertidal areas, variations in fluorescence parameters due to changes in chl a concentrations are much greater than those due to photochemical and nonphotochemical quenching. In situ surveys during 3 seasons showed a daily bell-like periodicity in $F$, regardless of tidal oscillations. Sediment cores incubated at constant light and temperature displayed similar day/night fluorescence variations, indicating an endogenous rhythm, and that the diel cycle is the main factor triggering migration. Our results revealed a difference in the functioning of subtidal and intertidal MPB, in which migration is linked not only to diel but also to tidal cycles. In future studies of subtidal benthic primary production, care should be taken in sampling strategies, particularly in selecting sampling times, as the migratory behaviour of the MPB may greatly alter estimates of available or actively photosynthesising biomass.
\end{abstract}

KEY WORDS: Microphytobenthos $\cdot$ Migration $\cdot$ Fluorescence $\cdot$ Subtidal

Resale or republication not permitted without written consent of the publisher

\section{INTRODUCTION}

The recognised importance of the primary productivity of benthic microalgae in littoral zones (MacIntyre et al. 1996, Serôdio \& Catarino 2000) has led to an increased focus on understanding the dynamics of these communities (MacIntyre et al. 1996, Underwood \& Kromkamp 1999). Distinct assemblages colonise rocks, sediments and coral reefs, and inhabit intertidal and subtidal areas in almost all latitudes (MacIntyre et al. 1996, Barranguet 1997, Serôdio et al. 1997).

The primary production of microphytobenthos (MPB) is particularly high in intertidal mudflats (MacIntyre et al. 1996 and references therein, Barranguet 1997) and shallow subtidal sites (Miles \& Sundbäck 2000, Glud et al. 2002), representing a significant frac- 
tion of overall primary productivity in estuarine regions (MacIntyre et al. 1996, Underwood \& Kromkamp 1999). In addition, subtidal MPB regulate nutrient fluxes at the sediment-water interface (Sundbäck et al. 1991), forming an active filter and reducing the flow of nutrients into the pelagic zone (Facca et al. 2002).

Within intertidal sediments light is rapidly attenuated, and the photic depth is shallow (Guarini et al. 2000); thus photosynthesis and primary production occur when the MPB migrate to the surface of muddy sediments during daytime emersions (Paterson \& Crawford 1986, Janssen et al. 1999, Serôdio \& Catarino 2000). As tidal waters recede, microalgae quickly migrate to the sediment surface where they receive the maximum incident light energy available. This endogenous migratory rhythm is maintained when external physical synchronisers are removed (Palmer \& Round 1965, Serôdio et al. 1997). The migration results in the formation of a biofilm, which consists of a dense layer of cells at the mud surface (Paterson \& Crawford 1986). The composition of this biofilm may change during the course of the diel period due to the sequential micro-cycling of different MPB species (Underwood et al. 2005). Cells migrate into deeper sediments before the rising tide or at nightfall (Serôdio et al. 1997, Guarini et al. 2000). A portion of the biofilm has also been shown to remain on the surface during the rising tide (Paterson \& Crawford 1986, Janssen et al. 1999), resulting in the resuspension of cells into the water column (de Jonge \& van Beusekom 1995, Blanchard et al. 1997). In the pioneering work of Palmer \& Round (1965) on the migration of Euglena obtusa, the authors postulated that the MPB migrate under the influence of a permanent positive geotactic response which is overlaid by a rhythmic variation in phototaxis. In this and subsequent work (Round \& Palmer 1966) they concluded that the migration was fundamentally diurnal but that a superimposed tidal influence led to an alteration in this rhythm.

A substantial number of studies and reviews have been published on subtidal MPB and their role in the coastal system (Cahoon 1999 and references within), but the presence of a migratory dynamic in subtidal communities is virtually undocumented. Underwood et al. (1999) reported a visual change in the biomass of Gyrosigma balticum subtidal mats. Cells were observed on the sediment surface in the morning and evening but seemed to burrow into the sediment at midday when higher light irradiances reached the sediment surface. Glud et al. (2002), studying the MPB of an arctic fjord using pulse amplitude modulated (PAM) fluorometry, found no migratory movement for a range of irradiances applied in the laboratory, although motile genera were dominant. In their pri- mary production calculations, migration was not accounted for, although they did not exclude the possibility of such migration in situ.

If present, vertical migration of subtidal MPB, may differ from that of intertidal MPB as physical constraints in the 2 environments are completely different. Subtidal MPB are not subject to aerial exposure or to the drying out of sediments, and thus variations in light and temperature are much smaller and factors such as tidal stage and responses to available ambient light levels (Pinckey \& Zingmark 1991, Perkins et al. 2003) may have a different influence on their functioning than in intertidal MPB.

In the present study, our objectives were (1) to trace in situ variations in PAM fluorescence at the surface of subtidal sediment to assess if a migratory rhythm is present in benthic diatoms and, if so, (2) to determine the main driving factor behind this, based on experiments performed in controlled conditions in the laboratory.

\section{MATERIALS AND METHODS}

Study site. The Bay of Brest is a semi-enclosed marine ecosystem on the French Atlantic coast. The ecosystem is connected to coastal waters (Iroise Sea) by a narrow ( $2 \mathrm{~km}$ wide) and shallow $(40 \mathrm{~m})$ strait. It is a shallow-water ecosystem (average depth at the lowest sea level ca. $8 \mathrm{~m}$ ) with about half of its total area (ca. $180 \mathrm{~km}^{2}$ ) shallower than $5 \mathrm{~m}$. Main freshwater inputs come from 2 rivers, the Aulne (southern) and the Elorn (northern). Tidal oscillations induce short-term variability in hydrological parameters and increase water mixing (Chauvaud et al. 1996). Maximum tidal amplitude reaches $8 \mathrm{~m}$ during spring tides, which represents an oscillation of $40 \%$ of the high tide volume over the tidal cycle.

In situ measurements and sampling for laboratory experiments were undertaken at the Saint Anne site $\left(48^{\circ} 21^{\prime} 610^{\prime \prime} \mathrm{N}, 4^{\circ} 33^{\prime} 000^{\prime \prime} \mathrm{W}\right)$, Bay of Brest, in August and November 2003 and May, July and September 2004. During the study periods, the tidally controlled water depth varied between ca. 4 and $11 \mathrm{~m}$. The median grain size of the muddy sediments at the site was $100 \mu \mathrm{m}$, with $29 \%$ of the sediment being $<63 \mu \mathrm{m}$. The site is sheltered on 3 sides, hence resuspension of sediment and effects of currents are minimal.

Fluorescence measurements. An underwater fluorometer 'Diving PAM' (Heinz Walz) was used to record the fluorescence at the mud surface, in the field and in controlled conditions in the laboratory. PAM fluorometry has previously been used to study MPB vertical migration (Serôdio et al. 1997, Kromkamp et al. 1998, Serôdio 2003). A modulated (multiple turnover) red 
light from a light-emitting diode (LED) $(650 \mathrm{~nm}$, pulse width $3 \mu \mathrm{s}$, frequency $0.6 \mathrm{kHz}$ ) is applied to the cells and a sensor then detects the returned fluorescence that is emitted by the chl a present (see Maxwell \& Johnson 2000 for review). Several parameters can be measured: steady-state fluorescence in ambient light $(F)$, minimal fluorescence after a period of dark adaptation $\left(F_{0}\right)$, maximum fluorescence after a multiple turnover, saturating flash applied following dark adaptation $\left(F_{\mathrm{m}}\right)$, and maximum fluorescence after a multiple turnover saturating flash applied in ambient light without dark adaptation $\left(F_{\mathrm{m}}{ }^{\prime}\right)$, (see Kromkamp \& Forster [2003] for definitions and explications of all fluorescence parameters). The effective photochemical efficiency of Photosystem II (PSII) in light adapted cells can be calculated as (Genty et al. 1989):

$$
\Delta F / F_{\mathrm{m}}{ }^{\prime}=\left(F_{\mathrm{m}}{ }^{\prime}-F\right) / F_{\mathrm{m}}{ }^{\prime}
$$

$F_{0}$ can be used as a proxy for the phototrophic biomass as it is well correlated with the chl a concentration present (Serôdio et al. 1997, Barranguet \& Kromkamp 2000, Honeywill et al. 2002). It was however technically impossible to manipulate the system underwater to induce dark adaptation on a repetitive, short, time scale; therefore, $F$ was used in this study to track vertical migration of MPB at the sediment surface (Kromkamp et al. 1998, Perkins et al. 2001, Serôdio 2003). In all experiments, PAM fluorometer settings and the distance between the probe and the sediment surface $(10 \mathrm{~mm})$ were maintained constant. In order to limit the background fluorescence signal of the sediment, for each experiment, the auto-zero function of the PAM was performed for sediment samples taken at depths of $10 \mathrm{~cm}$. The following settings were applied for the duration of the experiment: light saturation intensity, 8; saturation width, $0.8 \mathrm{~s}$, out-gain, 8 ; light gain, 1 ; actinic intensity, 5 ; damp, 2; measuring intensity, 8.

Three experiments were conducted:

Chlorophyll a (chl a) concentrations and F measurements at sediment surface: This first set of experiments consisted of measuring simultaneously the chl a concentration at the sediment surface (0 to $200 \mu \mathrm{m}$ ) and the steady-state fluorescence, $F$, of undisturbed cores, to determine whether in situ PAM fluorometer measurements could be used as a proxy for MPB biomass measurements. Sampling at the study site was carried out by SCUBA divers at sunrise, on 17 November 2003 ( 32 cores: 19 cores of $7 \mathrm{~cm} \varnothing$ and 13 of $5 \mathrm{~cm} \varnothing$ ) and on 7 May 2004 (9 cores, $5 \mathrm{~cm} \varnothing$ ). Cores were placed immediately in an outdoor incubation bath and were maintained at sea temperature $\left( \pm 0.5^{\circ} \mathrm{C}\right)$ by a continuous flow of seawater. Neutral nickel screens attenuating $50 \%$ of the incident light were placed over the cores to replicate in situ luminosity. Photosynthetically active radiation (PAR) was recorded in the incubation bath.

For each measurement, cores were removed from the incubation bath. Subsamples ( 2 from each $7 \mathrm{~cm} \varnothing$ core and 1 from each $5 \mathrm{~cm} \varnothing$ core) were taken using polycarbonate tubes of $3 \mathrm{~cm} \varnothing$. In November a total of 51 subsamples were acquired and in May, 9 subsamples were extracted. The tubes were first placed at the surface of the sediment to mark the area of sampling, and $F$ measurements were then made within each mark. The tubes were subsequently pushed into the sediment and the surface of each subsample was frozen with liquid nitrogen (Wiltshire et al. 1997). The frozen subsamples were stored at $-80^{\circ} \mathrm{C}$ until treatment and were freeze-dried within the following $48 \mathrm{~h}$. The topmost $200 \mu \mathrm{m}$ (considered as the sediment depth to which fluorescence is detectable by the Diving PAM fluorometer; Kromkamp et al. 1998, Honeywill et al. 2002) was cut using a freezing cryotome (LEICA, CM 1900). As a result of the extremely difficult and fine technique involved in the handling and cutting of such a thin layer of sediment, only 35 out of the 51 cores in November and 7 out of the 9 cores in May were used in the experiment. Reasons for exclusion of samples included disintegration of surface layers during freezedrying, breakage of sediment surface layers while cutting, and uneven surface that made precise cutting impossible.

The chl $a$ in the cut layer was estimated using the method of Lorenzen (1966); $10 \mathrm{ml}$ of $90 \%$ acetone was added to each sample that was then kept in the dark and in constant agitation, at $4{ }^{\circ} \mathrm{C}$, for approximately $18 \mathrm{~h}$. Subsequently, samples were centrifuged for $5 \mathrm{~min}$ at $2000 \mathrm{rpm}(402 \times g)$. Chl $a$ and phaeopigment concentrations were measured in the supernatant before and after acidification, respectively, with a KONTRON fluorometer (Kontron Instruments).

In situ fluorescence measurements: In the second set of experiments, the diving PAM fluorometer was positioned at the sediment surface by SCUBA divers and programmed to record automatically. In situ fluorescence parameters $\left(F, F_{\mathrm{m}}{ }^{\prime}\right)$ were measured over a daylight photoperiod in November 2003 and two $48 \mathrm{~h}$ periods in July and September 2004, respectively. $\Delta F / F_{\mathrm{m}}{ }^{\prime}$ (Eq. 1) was calculated from the collected data. Environmental variables at the sediment surface (PAR, temperature, water depth, salinity) were recorded simultaneously. Throughout each manipulation, the PAM measuring probe was positioned and maintained by a frame at $10 \pm 1 \mathrm{~mm}$ from the sediment surface. Measurements were programmed at 15 min intervals, to prevent undesirable stress effects of repeated saturation pulses on the MPB such as modification of migration, or lack of relaxation of the primary electron acceptors after excitation. At the end of the observa- 
tion period the PAM fluorometer was brought to the surface and the data were downloaded. Results are presented as average hourly values.

PAR was recorded at the sediment surface with a Licor quantameter (LI-192SA, Li-COR) connected to a Licor 1400 data logger. Water depth (m), salinity and temperature $\left({ }^{\circ} \mathrm{C}\right)$ were recorded at the study site using the YSI 6920 multi-parameter logging system.

On 28 July a core was sampled and incubated outside the laboratory to record the visual changes in surface colour and thus surface cover of MPB. Seawater, pumped directly from the site, was circulated gently around the core to avoid disruption of the sedimentwater interface. The combination of neutral nickel screens (as used in the first experiment) and the constantly flowing water ensured that the core was kept as close to in situ conditions as possible. Over a $24 \mathrm{~h}$ period (29 July) the core surface was photographed at $2 \mathrm{~h}$ intervals.

Laboratory experiments on cores exposed to constant light and temperature: The third series of experiments was undertaken in the laboratory and consisted of measuring continuously the surface fluorescence ( $F$ and $F_{\mathrm{m}}{ }^{\prime}$ ) of cores maintained in controlled and constant conditions of light and temperature, in order to determine the presence of an endogenous rhythm within the MPB. On 8 August and 14 November 2003, a core was extracted from the Saint-Anne site and taken immediately to the laboratory and placed under constant light $\left(17 \mu \mathrm{mol} \mathrm{m} \mathrm{m}^{-2} \mathrm{~s}^{-1}\right)$ and temperature $\left(13^{\circ} \mathrm{C}\right)$. After adjusting the level of overlying seawater to $10 \mathrm{~cm}$, the PAM was set to record fluorescence values every 15 min during a $48 \mathrm{~h}$ period. On 14 November, after a dark adaptation period of $15 \mathrm{~min}, F_{0}$ was measured every $2 \mathrm{~h}$ from 11:00 to 19:00 h.

On 13 November, 1 additional core was taken for a qualitative determination of MPB species at the sediment surface. The cells, resuspended in filtered seawater, were examined using an inverted microscopy (Leica DM IRB).

\section{RESULTS}

\section{Relationship between chl a concentrations and $F$}

The variations in chl a concentrations $\left(\mathrm{mg} \mathrm{chl} a \mathrm{~m}^{-2}\right)$ in the topmost $200 \mu \mathrm{m}$, as a function of $F$ measurements, in May 2004 and November 2003 are shown in Fig. 1. The PAM settings and distance of the probe from the sediment surface were identical, enabling comparisons between the 2 seasons. $\mathrm{Chl}$ a concentrations over the 2 seasons ranged between 0.3 and $16.9 \mathrm{mg} \mathrm{m}^{-2}$, but concentrations in November ( 0.3 to $1.4 \mathrm{mg} \mathrm{chl} \mathrm{a} \mathrm{m}^{-2}$ ) were

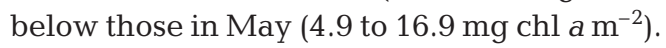

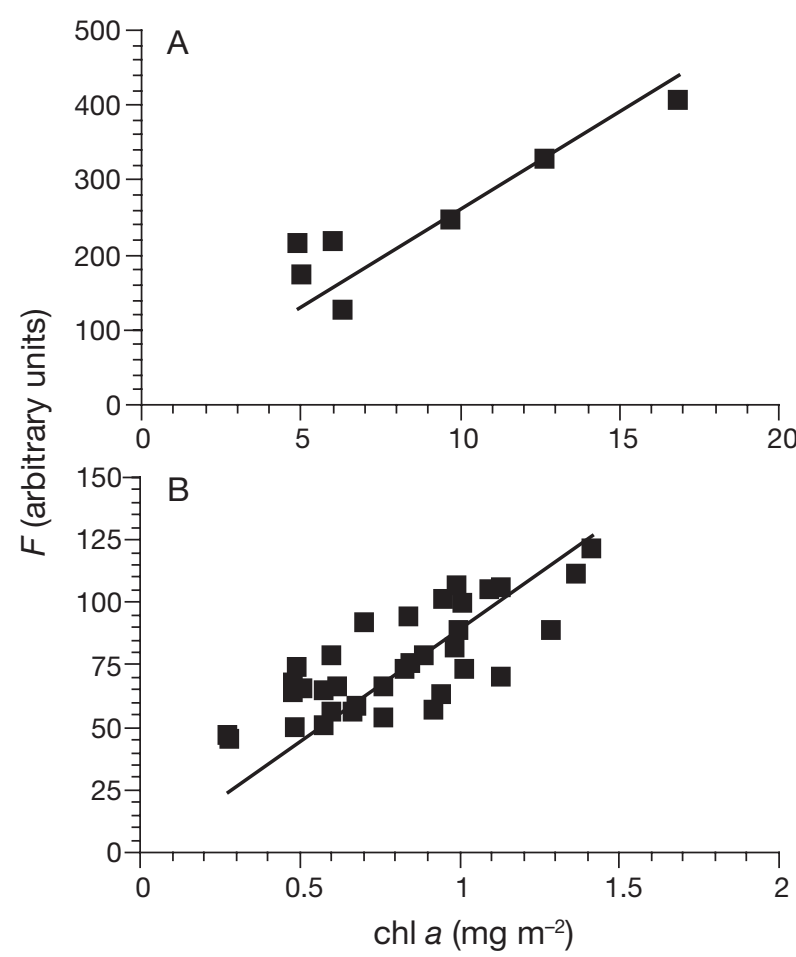

Fig. 1. Relationship between chl a concentrations and steadystate fluorescence $(F)$ measured in cores taken from the Saint Anne site, Bay of Brest, France, in (A) May 2004 and (B) November 2003 ( $p<0.01$ in both cases)

As $F$ and chl a both showed lower values in November than in May, and the 2 data sets did not overlap, they were analysed separately. The relationships between chl a concentrations and $F$ values were investigated using linear regression models (Statgraph statistical computer program). For both sets of experiments $F$ was significantly correlated with the chl a concentration $(\mathrm{p}<0.01)$. The resultant model equations were:

$$
\begin{aligned}
\operatorname{chl} a\left(\mathrm{mg} \mathrm{m}^{-2}\right)= & 0.04( \pm 0.01) \times F-0.89( \pm 1.39) \\
& \left(\mathrm{r}^{2}=0.89\right) \text { for May } \\
\operatorname{chl~} a\left(\mathrm{mg} \mathrm{m}^{-2}\right)= & 0.01( \pm 0.01) \times F-0.01( \pm 0.10) \\
& \left(\mathrm{r}^{2}=0.67\right) \text { for November }
\end{aligned}
$$

Unilateral Fisher F-tests showed a significant difference between the slopes for the 2 seasons and their respective intercepts at the origin (Proba $\left\{F<F_{0.01} / H_{0}\right\}$ $<0.01$ ): the slope of the May data was steeper than that of the November data, and the intercept at the origin was higher.

Taxonomic identification of cells at the sediment surface revealed that the genus Gyrosigma represented the largest number of cells. G. attenuatum and G. fasciola were identified along with other benthic diatoms such as Pleurosigma sp., Melosira sp., Navicula spp., Berkeleya spp., Amphora sp. and Cocconeis spp. 


\section{Variations of in situ fluorescence parameters}

Variations in $F, F_{\mathrm{m}}{ }^{\prime}$ and $\Delta F / F_{\mathrm{m}}{ }^{\prime}$ (Eq. 1) as a function of light and tidally controlled water depth, were followed in summer (July and September) and in autumn (November) (Fig. 2). Between the 2 seasons, the average daily PAR decreased by a factor of 5 (from 57 to $12 \mu \mathrm{mol}$ quanta $\mathrm{m}^{-2} \mathrm{~s}^{-1}$ ). Average water temperature decreased from $18.08 \pm 0.35$ to $13.08 \pm 0.12^{\circ} \mathrm{C}$, and salinity fluctuated slightly between $35.33 \pm 0.28$ and $34.24 \pm 0.04 \%$ o (data not shown).

Measurements on 28 and 29 July (Fig. 2A,B) were carried out continuously throughout 2 full diurnal cycles. The tidal cycle on 28 July resulted in an increase in the depth of water over the study site from 5.5 to $8.9 \mathrm{~m}$ from the beginning of the observations to high tide at 14:47 h. A similar tidal cycle was observed for the second day with high tide at 15:53 $\mathrm{h}$ (water depth $9.3 \mathrm{~m}$ ). $F$ increased immediately after sunrise (around 07:00 h) and then followed a bell-shaped curve. On 28 July the maximum $F$ value (731 arbitrary units, a.u.) was reached at 16:49 h, approximately $2 \mathrm{~h}$ after local noon (mid-point between dawn and dusk), when the tide was receding. During the second daily cycle, although the daily peak is difficult to see on the presented graph (Fig. 2A), the data showed that fluorescence peaked about the same time as on the previous day, with similar amplitude, despite a $1 \mathrm{~h}$ shift in the time of high tide.
A stable minimum value was reached on the first day after midnight (00:37 h) with $F$ values remaining close to 200 a.u. for the rest of the night. PAR at the sediment surface had reached its minimum value $(<10 \mu \mathrm{mol}$ quanta $\mathrm{m}^{-2} \mathrm{~s}^{-1}$ ) approximately $2 \mathrm{~h}$ earlier at 22:00 h. On the second day, recordings of fluorescence and PAR were stopped at 21:25 h ( $F=292$ a.u. $)$. At this time, $F$ values were similar to those for the same period on the previous day.

The expected cyclical change in PAR for both days showed several irregularities. Fluorescence was unaffected by the anomalies in the curve with the exception of the second day when a large increase in PAR from 58 to $224 \mu \mathrm{mol}$ quanta $\mathrm{m}^{-2} \mathrm{~s}^{-1}$ between 09:00 and 11:00 h, coincided with a noticeable increase in $F$ from 433 to 947 a.u.

Fig. 2B illustrates the variation in $F_{\mathrm{m}}{ }^{\prime}$ and $\Delta F / F_{\mathrm{m}}{ }^{\prime}$ throughout the $2 \mathrm{~d}$ period in July. Both parameters showed persistent oscillations synchronised with the day-night cycle. $F_{\mathrm{m}}$ ' demonstrated a rapid and large increase concomitant with a rise in $F . F_{\mathrm{m}}$ ' reached values of 2105 and 2549, respectively on Days 1 and 2, corresponding to an increase in $F_{\mathrm{m}}{ }^{\prime}$ of 350 to $486 \%$ from the initial value and from the previous night's measurements. $F_{\mathrm{m}}$ ' then declined at the same time as the PAR and remained constant (around 500 a.u.) during the night. The PAR anomaly on the second day also influenced $F_{\mathrm{m}}$ '.

The effective photochemical efficiency of PSII $\left(\Delta F / F_{\mathrm{m}}^{\prime}\right)$ showed a $30 \%$ variation throughout the day:
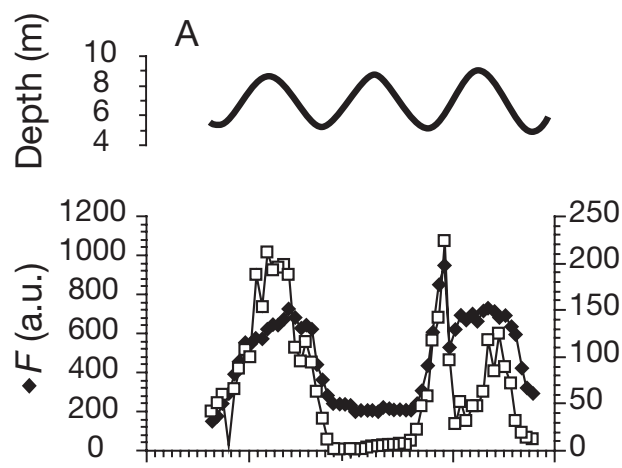

$\mathrm{B}$

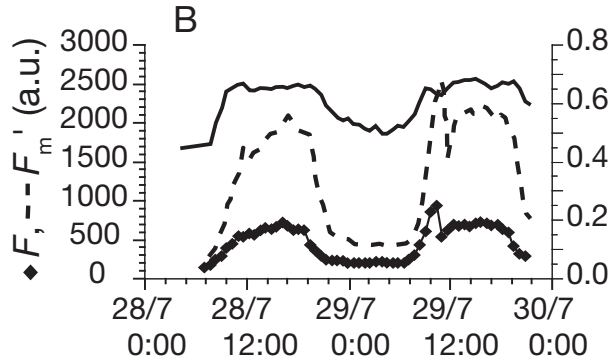

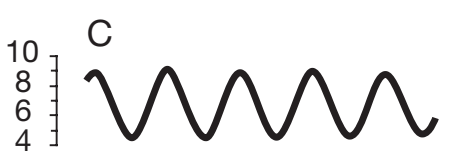
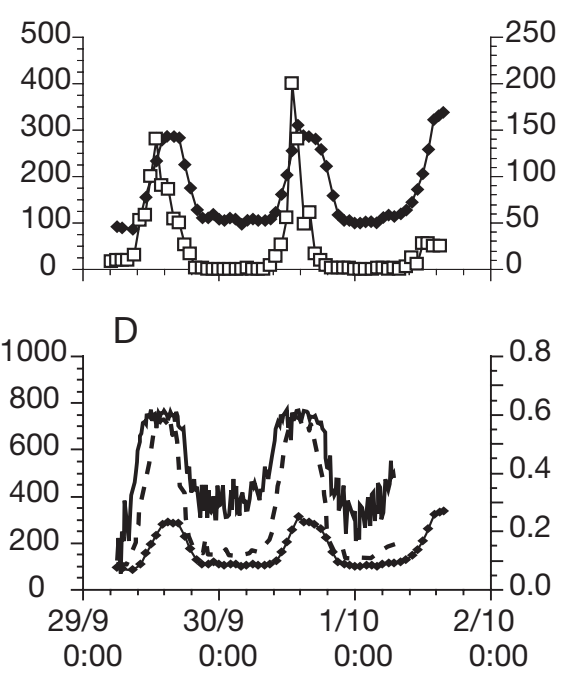
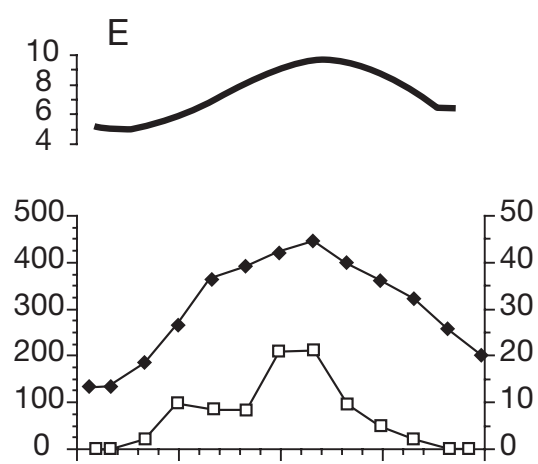

$\mathrm{F}$

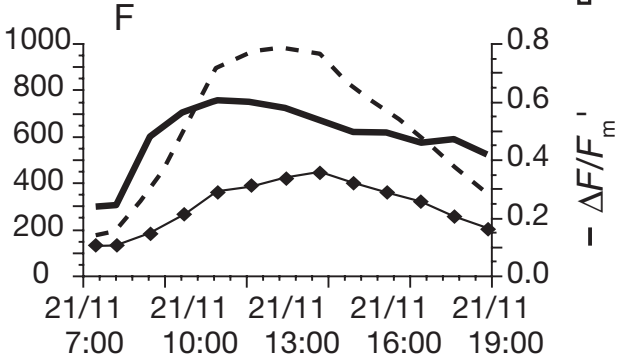

Time (date, hour)

Fig. 2. Tidally controlled water depth, PAR and superficial sediment fluorescence parameters $F, F_{\mathrm{m}}{ }^{\prime}$ and $\Delta F / F_{\mathrm{m}}{ }^{\prime}$ measured in situ at the Saint Anne site in $(A, B)$ July, and $(C, D)$ September 2004 and $(E, F)$ November 2003. Dates given as d/mo; a.u.: arbitrary units 
from 0.47 to 0.68 . As for $F_{\mathrm{m}}^{\prime}$, a sharp increase was observed at the night-day transition. During the day, the efficiency remained relatively constant, with only slight variability, until a steady decrease began at 20:00 h. Night time observations revealed continuous small amplitude fluctuations in the efficiency. Changes in $F$ and $F_{\mathrm{m}}$ ' arising from the peak in measured PAR on the morning of the second day resulted in a very slight dip in efficiency.

In September, fluorescence parameters and PAR were recorded over 2 full days (Fig. 2C,D). Tidal conditions were the reverse of those in the previous experiment, with low tide occurring at 13:00 h $(4.74 \mathrm{~m})$ and 13:54 h (4.87 m) on 29 and 30 September, respectively. Variations in $F$ were in a narrower range (from 105 to 300 a.u.) than in July (max. 730 a.u.), whereas PAR was only slightly lower and did not exceed $155 \mu \mathrm{mol}$ quanta $\mathrm{m}^{-2} \mathrm{~s}^{-1}$. Highest PAR values were around 13:00 $\mathrm{h}$ on both days; local noon was at 15:30 h. However, despite the reversal of tidal oscillations, the shape of the $F$ curve was identical to that in July. $F$ increased at sunrise $(08: 50 \mathrm{~h})$, reached a maximum approximately $2 \mathrm{~h}$ after local noon $(17: 00 \mathrm{~h})$, and decreased until it reached a stable base value $(F=102$ a.u. $)$ at dusk.

$F_{\mathrm{m}}{ }^{\prime}$ and $\Delta F / F_{\mathrm{m}}{ }^{\prime}$ displayed large changes throughout the photoperiod (Fig. 2D). $F_{\mathrm{m}}$ ' increased from $155 \mathrm{a}$.u. during the hours of darkness to a maximum of $720 \mathrm{a}$.u. on 29 and 30 September. Similarly, $\Delta F / F_{\mathrm{m}}{ }^{\prime}$ increased considerably, increasing from 0.36 to 0.61 a.u. and from 0.43 to 0.60 a.u. between night and day for Days 1 and 2, respectively. It then remained fairly constant throughout the light period until decreasing in correspondence to the drop in $F$ and $F_{\mathrm{m}}$ '.

The November observation (Fig. 2E,F) demonstrated similar curves with, however, smaller amplitudes than in July and September. Lower light intensities and shorter daylight exposure were experienced, and local noon was close to 13:00 h. These seasonal factors were clearly reflected in the fluorescence curves by lower values and a shorter curve period. The peak in $F$, although lower than in the summer and early autumn periods, occurred approximately $1 \mathrm{~h}$ after local noon (13:44 h on 21 November; $F=457$ a.u.) while tidal oscillations resulted in a high tide at 14:38 h. Nightfall occurred at 18:00 $\mathrm{h}$ and final data logging was at 19:00 h with a recorded fluorescence of 132 a.u.

$F_{\mathrm{m}}$ ' rose steadily from $08: 00 \mathrm{~h}$, until a maximal value at 11:00 h of 903 a.u. (Fig. 2F). A steady state was maintained until the descent began at 14:00 $\mathrm{h}$ and the final recording showed a value of 349 a.u. at 19:00 h. The slopes of both the $F_{\mathrm{m}}$ ' and $F$ curves governed the shape of the $\Delta F / F_{\mathrm{m}}{ }^{\prime}$ curve, which rose with a relatively steep slope until 09:00 $\mathrm{h}$ and then continued to increase more slowly until 12:00 $\mathrm{h}\left(\Delta F / F_{\mathrm{m}}{ }^{\prime}=0.60\right)$, declining after this point to 0.42 at 19:00 h.

\section{Visible changes in surface biofilm concentration}

Cores taken from the site and photographed over the course of $1 \mathrm{~d}$ showed a visible change in surface colour over the photoperiod (Fig. 3). At 07:00 h the sediment surface was an homogenous pale brown. At 13:00 h darker brown areas had appeared at the surface. Variability was evidenced by the lack of colour homogeneity at the sediment surface. As the day advanced a change in the surface colour patchiness was seen (15:00 h) with a slight but visible reduction in the diameter and intensity of the dark brown areas. At 19:00 h the colour had changed as the sediment surface became more visible, and there was a clear contrast to the early afternoon situation.

\section{Diel surface fluorescence changes under constant light and temperature}

Variations in surface $F$ values observed in constant conditions (Fig. 4) showed that when cores were placed in constant light and temperature, $F$ remained synchronised with the light/dark cycle. On 7 August 2003 (Fig. 4A) fluorescence measurements began at 15:00 h. The signal decreased to a minimum ( $F=222$ a.u. at 00:30 h) during the rising tide. The following day fluorescence started to increase at 05:30 h. The maximum on 8 August ( $F=778$ a.u.) was observed $2 \mathrm{~h}$ after local noon, similar to in situ observations for the same season. High tide on 8 August was at 15:46 h. On the evening of 8 to 9 August, $F$ values did not appear to attain a steady base line but rather an inflection was noted, with $F$ dropping to a minimum of 462 a.u. at $02: 30 \mathrm{~h}$ and then beginning to rise again. A similar overall trend in $F$ and $F_{\mathrm{m}}$ ' was evident, with an increase in peak measurements from Days 1 to 2 resulting in a $100 \%$ increase. $\Delta F / F_{\mathrm{m}}{ }^{\prime}$ varied from morning to evening from 0.36 to 0.61 , and from 0.43 to 0.60 , on Days 1 and 2 , respectively. Calculated $\Delta F / F_{\mathrm{m}}{ }^{\prime}$ was similar for all photoperiods and the efficiency peak appeared to be consistent between days.

The replicate experiment on 14, 15 and 16 November (Fig. 4B) showed a similar pattern, despite a converse in situ tidal situation: low tide coinciding this time with local noon. Although laboratory light and temperature conditions were identical to those in August, $F$ values in November remained in a lower range. After reaching a maximal value of 282 a.u., fluorescence began to decrease at $14: 25 \mathrm{~h}$, about $1 \mathrm{~h}$ 30 min after local noon. A baseline of $F$ was reached at 19:24 h ( $F=128$ a.u.), similar to in situ measurements, and subsequently rose again at 05:30 h. The peak for the second day similarly took place at 14:30 h with a value of 321 a.u. On this day, minimum stable values 

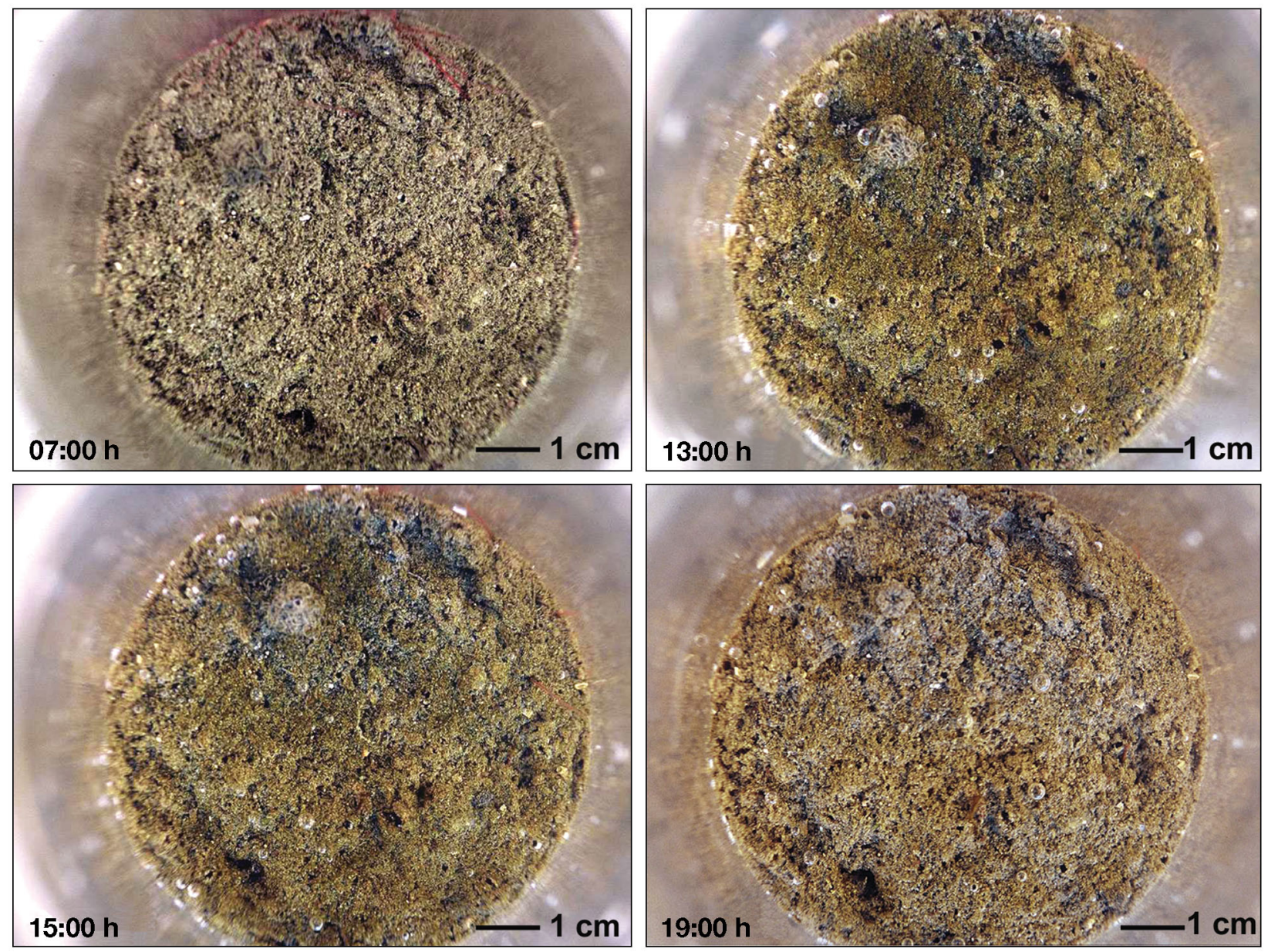

Fig. 3. Colour change in the surface of a sediment core throughout a day (29 July 2004)

were reached at 21:30 h. Maximum and minimum $F$ values increased in both seasons from the first to the second day of the experiment. $F_{0}$, measured on the 14 November, followed the $F$ curve closely, with values remaining just below those of $F$. Light-adapted $F_{\mathrm{m}}$ ' and calculated $\Delta F / F_{\mathrm{m}}{ }^{\prime}$ curves were comparable to those recorded on 29 and 30 September in situ, with a considerable elevation in both parameters during the daytime.

\section{DISCUSSION}

\section{$F$, a tool to estimate benthic chl a biomass in the subtidal zone}

The majority of previous studies of MPB biomass used a greater sampling depth than this study, and so direct comparisons are somewhat difficult. However, the concentrations presented here are in the lower range of MPB biomass estimates, using different techniques of collection and sampling depths, compiled in the review by MacIntyre et al. (1996), who cited values

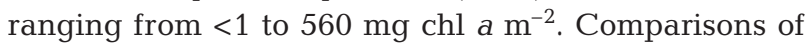
the results of previous studies using similar methods of extraction and, more importantly, replicate sediment depths, show that the concentrations in this study are in the range of values presented by Herlory et al. (2004) but are in the lower range of MPB biomass estimates given by Honeywill et al. (2002) for the same sediment sampling depth in 2 European intertidal sites.

Comparison with the biomass of phytoplankton in the overlying waters shows that MPB is of great importance to the ecosystem as it may represent as much as one-third of the maximum biomass observed in the water column in the Bay of Brest during the spring bloom (authors' unpubl. data).

Our results demonstrate that under the experimental conditions of this study the application of PAM fluorometry to subtidal sediments permits the detection of 

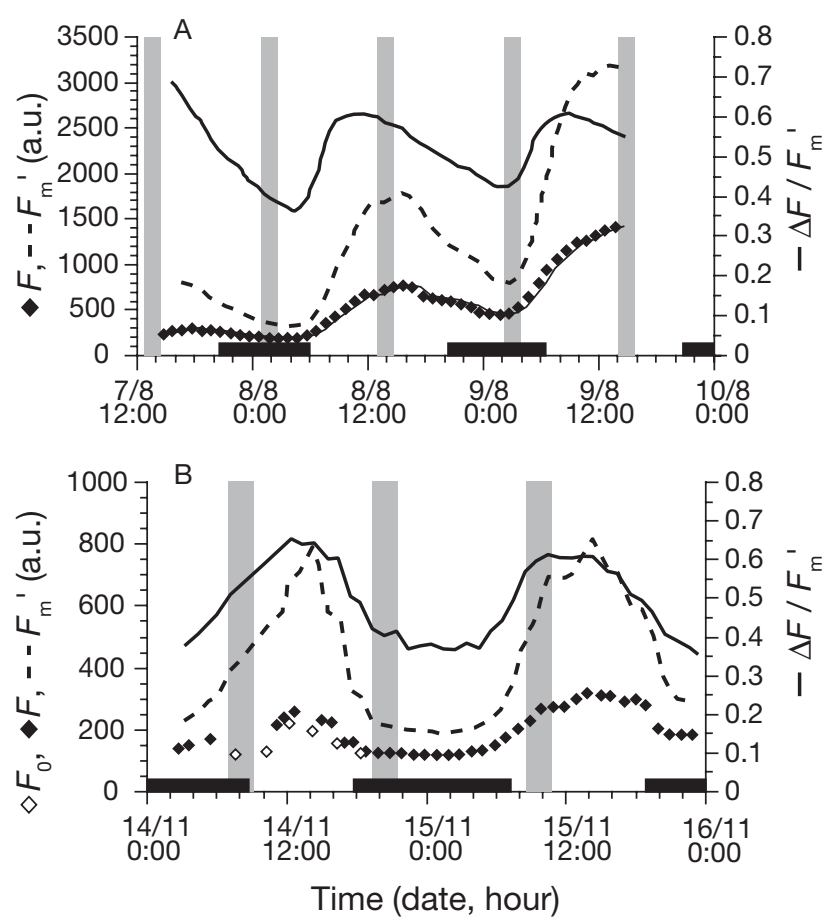

Fig. 4. $F, F_{\mathrm{m}}{ }^{\prime}$ and $\Delta F / F_{\mathrm{m}}{ }^{\prime}$ changes measured in cores sampled from the Saint Anne site in (A) August and (B) November 2003, and kept at constant temperature and light conditions. $F_{0}$ was also measured on 14 November between 11:00 and 19:00 h. Vertical shaded bars: high-tide periods; horizontal black bars: night times (recorded in situ)

large fluctuations in $F$ at the sediment surface, and that such variations can be attributed to changes in chl a concentrations in the upper layers of the sediment caused by vertical migration of cells. Regardless of its slope and intercept, the significant linear correlation $\left(\mathrm{r}^{2}=0.89, \mathrm{p}<0.01\right.$, in May) between $F$ and chl a concentrations allows estimation of the relative variation, or rates of variation, of chl $a$ in this zone directly from the in situ measured value of $F$.

The correlation in November (Fig. 1B), although statistically consistent, showed a larger part of the variance unexplained by the linear regression model $\left(\mathrm{r}^{2}=\right.$ $0.67, \mathrm{p}<0.01)$. Significant seasonal differences were observed for the slopes of the 2 linear relationships between $F$ and chl a concentration. These differences might be related to shifts in the average ecophysiological condition of the community, background fluorescence, changes in taxonomic composition and/or temperature (Kromkamp et al. 1998).

In cases of low chl a concentrations, such as those in Fig. 1B, a deviation of the apparent fluorescence measurements from the actual concentration in the sediments sampled can occur (Forster \& Kromkamp 2004). The influence of cells positioned at deeper levels within the sediment can have an affect on the fluores- cence measured, leading to inaccurate results and hence a low correlation with the chl a measured. However, the results do suggest that $F$ can be used to estimate the microalgal biomass, but care must be taken to validate measurements for each site and season.

\section{Evidence of migration}

The migratory pattern of benthic diatoms was first evidenced by the evolution of the surface colour of sediment cores (Fig. 3). Colouration of the sediment is a general indicator of the nature of the sediment surface, although it is dependent on subjective perception. Algal cells accumulate at the surface layer of the sediment in sufficient density to impart a visible dark brown colouration to the substratum. Areas where the sediment appears dark brown are generally dominated by diatom assemblages (Paterson et al. 1998). This colouration appeared to be maximal around local noon and disappeared in the afternoon (Fig. 3). Although these visual observations of the evolution of the algal biomass at the sediment surface are non-quantitative, they are consistent with in situ fluorescence measurements. During all our observations, $F$ began to increase shortly after sunrise, peaked 1 or $2 \mathrm{~h}$ after local noon, and then decreased down to a constant base value, reached a few hours after complete darkness (Fig. 2). The photographic evidence thus corroborates that the variations observed in $F$ are related to variations in chl $a$ at the surface layer of the sediment.

However, a number of factors need to be considered to interpret PAM fluorometry parameters; for example Serôdio et al. (2001) concluded that $F$ and $F_{\mathrm{m}}{ }^{\prime}$ are clearly inadequate for tracing variations of biomass in MPB samples because $F$ can rise with light and potentially decrease with high light as various photochemical and non-photochemical quenching mechanisms come into operation. Irradiance increases can result in the closure of reaction centres, increasing fluorescence re-emitted by cells and thus augmenting $F$ measurements. Conversely, non-photochemical quenching (NPQ) processes, often induced by high light, evoke the reversible de-epoxidation reaction which converts the xanthophyll cycle pigment diadinoxanthin (DD) to the energy dissipating form diatoxanthin (DT), resulting in the dissipation of excess energy in the form of heat and hence a decrease in $F$ and $F_{\mathrm{m}}{ }^{\prime}$ (Kromkamp et al. 1998, Müller et al. 2001, Perkins et al. 2001, 2003). Serôdio et al. (2001) were however referring to the variability in the relationship between fluorescence intensity and chl a concentration as a function of large variations in temperature $\left(5\right.$ to $35^{\circ} \mathrm{C}$ ) and light $(200$ to $2200 \mu \mathrm{mol} \mathrm{m}{ }^{-2} \mathrm{~s}^{1}$ ) that characterise the estuarine intertidal environment (Serôdio \& Catarino 2000). In com- 
parison, variations in the subtidal environment of the present study are much less: temperature variations were lower than $1^{\circ} \mathrm{C}$ and maximum light irradiance was $250 \mu \mathrm{mol} \mathrm{m} \mathrm{m}^{2} \mathrm{~s}^{-1}$, and hence the MPB cells were presumed not to be light-saturated. Thus, our results show that there is a change in chl a concentrations at the sediment surface, leading to variation in $F$ that is much greater than any variation that could arise from physiological responses to light and temperature variations. In order to obtain a more detailed conception of the physical movements of the community, $F_{\mathrm{m}}$ ' was measured simultaneously with $F$ and $\Delta F / F_{\mathrm{m}}{ }^{\prime}$ subsequently calculated (Eq. 1).

$F_{\mathrm{m}}{ }^{\prime}$ increased above $F_{\mathrm{m}}$ levels in all observation months (Fig. 2), a phenomenon previously described for diatom cultures (Jakob et al. 1999). Under low light conditions, following a period of dark adaptation, the activation of ATP synthase and carbon metabolism can dissipate the proton gradient, leading to a gradual expoxidation of DT to DD (Jakob et al. 1999). The overall outcome is an increase in the light-capturing pigment (DD) and hence an increase in $F_{\mathrm{m}}{ }^{\prime}$ above $F_{\mathrm{m}}$. The increases in $F_{\mathrm{m}}{ }^{\prime}$ in our study were however extremely high (between 350 and $486 \%$ of nighttime values) and are thus considered too high to be exclusively a result of epoxidation. A more probable reason for the rise in $F_{\mathrm{m}}{ }^{\prime}$ is an increase in the number of viable cells at the sediment surface arising from vertical migration. Decreasing light during the second part of the day would rationally lead to an increase in $F_{\mathrm{m}}$ ' in stationary cells (Perkins et al. 2001) through the conversion of DT to $\mathrm{DD}$ and hence an increase in $F_{\mathrm{m}}{ }^{\prime}$; however a decrease was noted in our observations.

In all 3 observation months, a plateau was recorded in the efficiency of the MPB during the photoperiod, showing that light effects on fluorescence measurements were extremely low. High electron transfer rates, caused by exposure to high PAR levels will normally decrease efficiency because of the closure of Reaction Centre II and the stimulation of NPQ. The absence of a decrease in efficiency during the daytime suggests a lack of these 2 processes. The similarity of daytime values between days indicates that the physiological state of the MPB was constant.

During nighttime periods, an enforced natural dark adaptation of the cells results in measurements of the maximal $\left(F_{\mathrm{v}} / F_{\mathrm{m}}\right)$ rather than effective photochemical efficiency of PSII (Kromkamp \& Forster 2003). The fact that this value is lower than effective PSII efficiency measured during the day again shows that fluorescence measured during the day and that measured during the night does not emanate from the same community of cells. Measurements during the night might originate from cells that stay at the sediment surface, are less viable and incapable of migration. These nighttime values may also reflect degrading pelagic phytoplankton which sediment down through the water column and are re-mineralised at the sediment surface; however in the present study verification of the presence of pelagic cells was not undertaken.

These results show that the evolution of fluorescence measurements resulting from vertical migration is more important than temperature and irradiance effects on the physiology of the community. They indicate that, under subtidal environmental conditions, variations in $F$ and $F_{\mathrm{m}}$ ' represent primarily the evolution of chl a concentrations due to the migration of cells to the sediment surface, although care must be taken to re-determine the relationship for each site and season.

\section{What drives migration in the subtidal area?}

Our fluorescence measurements demonstrate a migratory cycle of subtidal MPB, with cells moving towards the sediment surface at the beginning of the photoperiod. Biomass reached a maximum 1 to $2 \mathrm{~h}$ after local noon, and thereafter decreased to a minimum value that remained fairly constant until sunrise the following day. Although fluorescence oscillations closely followed those of light, for unknown reasons, peaks in Flagged behind the highest daytime PAR values. However, fluorescence did appear to be closely correlated with photoperiod length. This is highlighted by the progression of day length with seasons: From July to November the photoperiod shortened as sunrise changed from 07:00 to 09:00 $\mathrm{h}$ and sunset from 23:30 to $17: 00 \mathrm{~h}$, leading to a reduction in day length from 16 to $8 \mathrm{~h}$. Similarly, local noon changed from 14:30 to $14: 00$ to $13: 30 \mathrm{~h}$ from July to September to November. This progression in the daylight period is reflected in the fluorescence results as a shortening (by a factor of 2) of the time the MPB spend at the sediment-water interface and a shift in the time when the maximum biomass is reached (from approximately 16:30 h in July to 14:00 $\mathrm{h}$ in November). Hence, the beginning of the photoperiod acts as a trigger for the initiation of migration, and the evolution of this period over time results in a concurrent temporal advancement in the starting point of migration and similar alterations in peak times.

The fluorescence data and photographic evidence show that at the subtidal mud surface of the study site, a constant evolution of the biomass occurs within the time frame of the photoperiod. Dynamically, vertical migration in some intertidal areas can be a fast and density-dependent process (Guarini et al. 2000), and biomass can be highly concentrated after a short time period (Herlory et al. 2004) resulting in a cohesive 
biofilm. In other intertidal sites the curve of migration can however be bell-shaped, similar to the results of this study (Serodio et al. 1997, 2000).

The existence of an endogenous rhythm within the cells is evidenced by the persistence of a bell-like migration (Fig. 4) in cores incubated in the laboratory in the absence of light variations. In both experiments (Fig. 4), F maxima were within in situ ranges and curves were synchronised with the photoperiod at the sampling site. Intertidal communities also show an internal regulation of migration when exposed to constant light (Round \& Palmer 1966).

During the second day of observations, $F$ values were higher than for the previous photoperiod, suggesting an increase or accumulation in the chl a concentration. MPB are subject to a number of phenomena in situ that result in a reduction or control of their biomass, such as feeding of benthic fauna and processes of resuspension (Blanchard 1998). In the laboratory there was an absence of these biomass-curtailing factors and hence an increase in the stock of MPB biomass is possible. Alternatively, the persistent exposure of the cells to light may have resulted in the upward migration of an increasing number of cells from deeper within the sediment during the course of the study.

The primary source of this migration in intertidal areas has been considered to be the interaction of a permanent positive geotaxis with a non-permanent rhythmic variation in phototaxis that is modulated by the available light (Palmer \& Round 1965, Round \& Palmer 1966). Hence, intertidal MPB migration is governed largely by tidal stage (Pinckey \& Zingmark 1991, Perkins et al. 2003) and diurnal cycles, which collectively control the available PAR present. In our study fluorescence measurements show no concurrence with tidal oscillations, and notwithstanding a reversal of the phase of the cycle from July and November to September no migratory deviation was recorded, confirming that in the subtidal area the diurnal rhythm alone prevails.

The vertical migration of MPB in most intertidal areas enables them to combat burial and erosion resulting from the often violent displacement of sediment, and thus allows them access to light and subsequent protection from resuspension during flood tides (Blanchard 1998). In the subtidal area, burying due to sedimentation of organic material from the pelagic zone may make the mobility of MPB essential, and would explain the migration of MPB towards the sediment surface with increasing daylight. The reason for the initiation of their downward migration so soon after midday is not known, but perhaps this migration pattern allows the cells sufficient time on the sediment surface to replenish their intracellular organic carbon before migrating deeper into the sediment (Underwood et al. 2005 and references therein) where they have access to the high nutrient concentrations of the interstitial waters (Saburova \& Polikarpov 2003).

\section{Implication of migration for primary production estimates}

The integration of migration processes into calculations of global primary production rates in intertidal areas can greatly modify estimates (Serôdio \& Catarino 2000), leading to significant alterations in daily and fortnightly timescales. In the subtidal, the vertical migration of MPB will also influence the fraction of total biomass at the sediment surface contributing to benthic production over the photoperiod. Application of the linear equation model to the in situ $F$ data allows theoretical quantification of the change in MPB biomass at the sediment surface. If we consider our data (Fig. 2), surface chl a concentrations could vary by more than a factor of 5 (from 5 to $28 \mathrm{mg} \mathrm{chl} \mathrm{a} \mathrm{m}^{-2}$ ) over a diel period. These values illustrate the large-scale differences in surface biomass possible during the migration process.

Approximations using fixed or migrating biomass concentrations will generate variability in model outputs of productivity. To illustrate this variability we integrated fixed and evolving chl a values into a theoretical production model over 1 photoperiod. A simplified model of a pre-existing exponential function (Webb et al. 1974), in which photo-inhibition was considered negligible, was used to calculate production:

$$
P_{B}=P_{\max }\left(1-\exp ^{\left(-E / E_{k}\right)}\right)
$$

where $P_{B}$ is the gross production rate $\left(\mathrm{mg} \mathrm{C} \mathrm{mg}^{-1} \mathrm{chl} \mathrm{a}\right.$ $\left.\mathrm{h}^{-1}\right), P_{\max }$ is the rate of maximum production $(\mathrm{mg} \mathrm{C}$ $\left.\mathrm{mg}^{-1} \mathrm{chl} a \mathrm{~h}^{-1}\right), E_{k}$ is the minimum saturating irradiance ( $\mu \mathrm{mol}$ quanta $\mathrm{m}^{-2} \mathrm{~h}^{-1}$ ), $E$ is the in situ irradiance over a diurnal period ( $\mu$ mol quanta $\mathrm{m}^{-2} \mathrm{~h}^{-1}$ ); measurements from July (Fig. 2A) were used for this latter parameter. As $P_{\max }$ and $E_{k}$ were unavailable for our study site, we used mean theoretical values from a study on benthic microalgae in a temperate area (Sundbäck \& Jönsson 1988) $\left(P_{\max } 1.07 \mathrm{mg} \mathrm{C} \mathrm{mg}^{-1} \mathrm{chl} \mathrm{a} \mathrm{h}{ }^{-1}\right.$ and $E_{k}$ $172 \mu \mathrm{mol}$ quanta $\mathrm{m}^{-2} \mathrm{~h}^{-1}$ ). Gross primary production (mg C m${ }^{-2} \mathrm{~h}^{-1}$ ) was then calculated by multiplying the production by the chl a concentration. Observed $F$ data from in situ experiments on 28 July (Fig. 2A) were used to obtain a hypothetical daily range of chl a concentrations. We tested 4 hypothetical scenarios, the first whereby migration of the MPB is integrated into calculations, and the other 3 whereby production is calculated using a constant biomass and sampling is considered to have taken place at midday (highest biomass, Scenario 2), mid-morning (mean biomass, Scenario 3) and night (lowest biomass, Scenario 4) periods. 
Differences in theoretic production curves for the 4 scenarios are apparent in Fig. 5. Accumulated daily production estimates vary considerably between scenarios; values of 148, 199, 103 and $38 \mathrm{mg} \mathrm{C} \mathrm{m}^{-2} \mathrm{~d}^{-1}$ were calculated for Scenarios 1, 2, 3 and 4, respectively. There is a $25 \%$ increase in daily production rates if the peak chl a concentration is considered rather than a concentration that evolves with migration. Moreover, a $200 \%$ increase in approximated production is seen if measurements are taken at highest as opposed to the lowest surface biomass times. Even when considering mid-morning chl a concentrations, production is underestimated by one-third. Overall, this theoretical exercise underlines the importance of correct biomass sampling strategies in subtidal studies and illustrates that a consideration of migration is necessary to avoid large and important errors in primary production estimates.

\section{CONCLUSION}

Although subtidal MPB have been the subject of many studies, and the presence of migration has been suggested (Underwood \& Kromkamp 1999, Glud et al. 2002), to our knowledge this is the first study to verify and quantify the presence of subtidal MPB migration. We can conclude that a migratory pattern exists in subtidal MPB that is closely linked to the diel cycle and can lead to large variations in their surface biomass.

The variability in environmental conditions of intertidal areas influences the evolution of the migration pattern; in subtidal sediments these environmental conditions and their respective variability are different, resulting in a migration that is influenced more by the photoperiod alone than by a combination of light and physical regimes. Further study into this phenom-

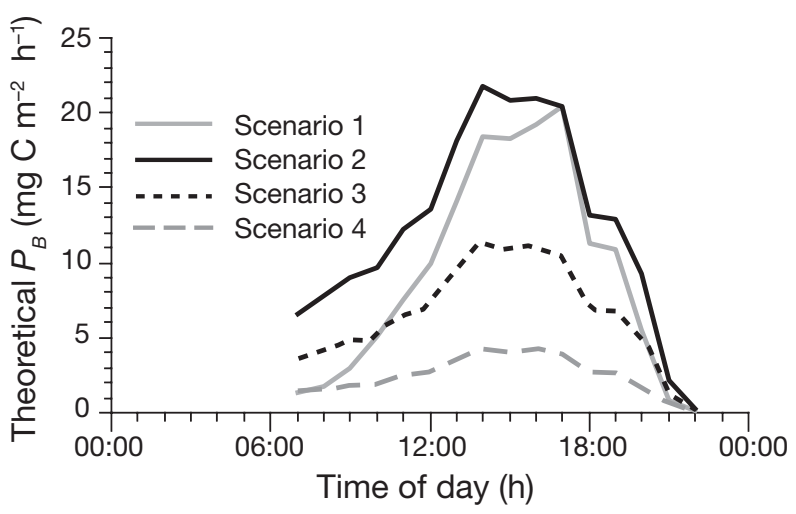

Fig. 5. Theoretical curves of primary production for migrating (Scenario 1), midday (highest biomass, Scenario 2), midmorning (mean biomass, Scenario 3) and night (lowest biomass, Scenario 4) biomass of microphytobenthos using chl a data transformed from in situ measurements in July 2004 enon is required to define processes previously proved in intertidal areas such as the stratification of cells in superficial sediments during the migration process (Herlory et al. 2004), the possible presence of a micromigration of different species at the sediment surface (Underwood et al. 2005) and the influence of internal rhythms governing the migration process. However, as in intertidal studies, this constant migration may affect estimates of available or actively photosynthesising biomass and, as illustrated by the theoretical model presented, care should be taken in selecting appropriate sampling times of surface sediments for accurate quantification of the role of this compartment in littoral ecosystems.

Acknowledgements. This work was funded by the Si-Webs (HPRN-CT-2002-00218) and ECCO European projects. From the LEMAR, the authors also thank J. Richard, S. Martin, G. Thouzeau and F. Jean for their help in core collection and the latter for his statistical aid, A. Le Mercier for his technical expertise during the photographing of cores and R. Marc and M. Briand for their help with the figures. The authors also thank J. Cloern (USGS, USA) for his careful reading, his fruitful comments and suggestions. Thanks are also due to those at the LBEM laboratory at the University of La Rochelle, for their assistance in sample analyses. This is contribution 1019 to the IUEM, European Institute for Marine Studies (Brest, France).

\section{LITERATURE CITED}

Barranguet C (1997) The role of microphytobenthic primary production in a Mediterranean mussel culture area. Estuar Coast Shelf Sci 44:753-765

Barranguet C, Kromkamp JC (2000) Estimating primary production rates from photosynthetic electron transport in estuarine microphytobenthos. Mar Ecol Prog Ser 204: $39-52$

Blanchard G (1998) Contrôle de la dynamique à court terme du microphytobenthos intertidal par le cycle exondationsubmersion. Ecologie 321:501-508

Blanchard GF, Guarini JM, Gros P, Richard P (1997) Seasonal effect on the relationship between the photosynthetic capacity of intertidal microphytobenthos and temperature. J Phycol 33:723-728

Cahoon LB (1999) The role of benthic microalgae in neritic ecosystems. Oceanogr Mar Biol Annu Rev 37:47-86

Chauvaud L, Thouzeau G, Grall J (1996) Experimental collection of great scallop postlarvae and other benthic species in the Bay of Brest: settlement patterns in relation to spatio-temporal variability of environmental factors. Aquac Int 4:263-288

de Jonge VN, van Beusekom JEE (1995) Wind and tide induced resuspension of sediment and microphytobenthos from tidal flats in the Ems estuary. Limnol Oceanogr 40:766-778

Facca C, Sfriso A, Socal G (2002) Temporal and spatial distribution of diatoms in the surface sediments of the Venice Lagoon. Bot Mar 45:170-183

Forster RM, Kromkamp (2004) Modelling the effects of chlorophyll fluorescence from subsurface layers on photosynthetic efficiency measurements in microphytobenthic algae. Mar Ecol Prog Ser 284:9-22 
Genty B, Briantais JM, Baker NR (1989) The relationship between quantum yield of photosynthetic electron transport and quenching of chlorophyll fluorescence. Biochim Biophys Acta 990:87-92

Glud RN, Kühl M, Wenzhöfer F, Rysgaard S (2002) Benthic diatoms of a high Arctic fjord (Young Sound, NE Greenland): importance for ecosystem primary production. Mar Ecol Prog Ser 238:15-29

Guarini JM, Blanchard GF, Gros P (2000) Quantification of the microphytobenthic primary production in European intertidal mudflats - a modelling approach. Cont Shelf Res 20:1771-1788

Herlory O, Guarini JM, Richard P, Blanchard GF (2004) Microstructure of microphytobenthic biofilm and its spatio-temporal dynamics in an intertidal mudflat (Aiguillon Bay, France). Mar Ecol Prog Ser 282:33-44

Honeywill C, Paterson DM, Hagerthey SE (2002) Determination of microphytobenthic biomass using pulse-amplitude modulated minimum fluorescence. Eur J Phycol 37:485-492

Jakob T, Gross, R, Wilhem C (1999) Activation of diadinoxanthin de-epoxidase due to a chloroplast proton gradient in the dark in the diatom Phaeodactylum tricornutum. Plant Biol 1:76-82

Janssen M, Hust M, Rhiel E, Krumbein WE (1999) Vertical migration behaviour of diatom assemblages of Wadden Sea sediments (Dangast, Germany): a study using cryoscanning electron microscopy. Int Microbiol 2:103-110

Kromkamp JC, Forster RM (2003) The use of variable fluorescence measurements in aquatic ecosystems: differences between multiple and single turnover measuring protocols and suggested terminology. Eur J Phycol 38:103-112

Kromkamp JC, Barranguet C, Peene J (1998) Determination of microphytobenthos PSII quantum efficiency and photosynthetic activity by means of variable chlorophyll fluorescence. Mar Ecol Prog Ser 162:45-55

Lorenzen CJ (1966) A method for continuous measurement of in vivo chlorophyll concentration. Deep-Sea Res 13:223-227

MacIntyre HL, Geider RJ, Miller DC (1996) Microphytobenthos: the ecological role of the 'secret garden' of unvegetated, shallow-water marine habitats, 1 . Distribution, abundance and primary production. Estuaries 19:186-201

Maxwell K, Johnson GN (2000) Chlorophyll fluorescence-a practical guide. J Exp Bot 51:659-668

Miles A, Sundbäck K (2000) Diel variation in microphytobenthic productivity in areas of different tidal amplitude. Mar Ecol Prog Ser 205:11-22

Müller P, Li XP, Niyogi K (2001) Non-photochemical quenching. A response to excess light energy. Plant Physiol 125: 1558-1566

Palmer JD, Round FE (1965) Persistent, vertical-migration rhythms in benthic microflora. I. The effect of light and temperature on the rhythmic behaviour of Euglena obtusa. J Mar Biol Assoc UK 45:567-582

Paterson DM, Crawford RM (1986) The structure of benthic diatoms assemblages: a preliminary account of the use and evaluation of low-temperature scanning electron microscopy. J Exp Mar Biol Ecol 96:279-289

Paterson, DM Wiltshire KH, Miles A, Blackburn J, Davidson I, Yates MG, McGrorty S, Eastwood JA (1998) Microbiological mediation of spectral reflectance from intertidal cohe-

Editorial responsibility: Otto Kinne (Editor-in-Chief), Oldendorf/Luhe, Germany sive sediments. Limnol Oceanogr 43:1207-1221

Perkins RG, Underwood GJC, Brotas V, Snow GC, Jesus B, Ribeiro L (2001) Responses of microphytobenthos to light: primary production and carbohydrate allocation over an emersion period. Mar Ecol Prog Ser 223:101-112

Perkins RG, Honeywill C, Consalvey M, Austin HA, Tolhurst TJ, Paterson DM (2003) Changes in microphytobenthic chlorophyll a and EPS resulting from sediment compaction due to dewatering: opposing patterns in concentration and content. Cont Shelf Res 23:575-586

Pinckney J, Zingmark RG (1991) Effects of tidal stage and sun angles on intertidal benthic microalgal productivity. Mar Ecol Prog Ser 76:81-89

Round FE, Palmer JD (1966) Persistent, vertical-migration rhythms in benthic microflora. II. Field and laboratory studies on diatoms from the banks of the River Avon. Mar Biol Assoc UK 46:191-214

Saburova MA, Polikarpov IG (2003) Diatom activity within soft sediments: behavioural and physiological processes. Mar Ecol Prog Ser 251:189-207

Serôdio J (2003) A chlorophyll fluorescence index to estimate short-term rates of photosynthesis by intertidal microphytobenthos. J Phycol 39:33-46

Serôdio J, Catarino F (2000) Modelling the primary productivity of intertidal microphytobenthos: time scales of variability and effects of migratory rhythms. Mar Ecol Prog Ser 192:13-30

Serôdio J, da Silva JM, Catarino F (1997) Non-destructive tracing of migratory rhythms of intertidal benthic microalgae using in vivo chl-a fluorescence. J Phycol 33:545-553

Serôdio J, da Silva JM, Catarino F (2001) Use of in vivo chlorophyll a fluorescence to quantify short-term variations in the productive biomass of intertidal microphytobenthos. Mar Ecol Prog Ser 218:45-61

Sundbäck K, Jönsson B (1988) Microphytobenthic productivity and biomass in sublittoral sediments of a stratified bay, southeastern Kattegat. J Exp Mar Biol Ecol 122:63-81

Sundbäck K, Enoksson V, Granéli W, Pettersson K (1991) Influence of sublittoral microphytobenthos on the oxygen and nutrient flux between sediment and water: a laboratory continuous-flow study. Mar Ecol Prog Ser 74: 263-279

Underwood GJC, Kromkamp J (1999) Primary production by phytoplankton and microphytobenthos in estuaries. Adv Ecol Res 29:93-153

Underwood GJC, Nilsson C, Sundback K, Wulff A (1999) Short-term effects of UVB radiation on chlorophyll fluorescence, biomass, pigments and carbohydrate fractions in a benthic diatom mat. J Phycol 35:656-666

Underwood GJC, Perkins RG, Consalvey MC, Hanlon ARM, Oxborough K, Baker NR, Paterson DM (2005) Patterns in microphytobenthic primary productivity: species-species variation in migratory rhythms and photosynthetic efficiency in mixed-species biofilms. Limnol Oceanogr 50: 755-767

Webb WL, Newton M, Starr D (1974) Carbon dioxide exchange of Alnus rubus. Oecologia 17:281-291

Wiltshire KH, Blakburn J, Paterson DM (1997) The cryolander: a new method for fine-scale in situ sampling of intertidal surface sediments. J Sediment Res 67:977-981

Submitted: November 4, 2005; Accepted: May 9, 2006

Proofs received from author(s): December 7, 2006 